\title{
Teaching reflection to teachers and students
}

\section{Nancy Magnani, Judith Donnelly}

Nancy Magnani, Judith Donnelly, "Teaching reflection to teachers and students," Proc. SPIE 9793, Education and Training in Optics and Photonics: ETOP 2015, 97931X (8 October 2015); doi: 10.1117/12.2223185

SPIE Event: Education and Training in Optics and Photonics: ETOP 2015, 2015, Bordeaux, France 


\title{
Teaching reflection to teachers and students
}

\author{
Nancy Magnani*a, Judith Donnelly ${ }^{\mathrm{b}}$ \\ ${ }^{a}$ EASTCONN, 376 Hartford Tpke., Hampton, CT $06247^{\text {b }}$ Three Rivers Community College \\ 36 Sycamore Ter., Windham, CT 06280
}

\begin{abstract}
In the state of Connecticut, classroom teachers are required to teach life, physical and earth science content aligned with Next Generation Science Standards (NGSS) and/or state science standards. In this paper, we will present the results of a year-long effort to improve the teaching and understanding of one small strand in the standards: reflection of light.
\end{abstract}

Keywords: Elementary science education; inquiry-based lessons, reflection, outreach

\section{INTRODUCTION}

EASTCONN is one of six non-profit Regional Educational Service Centers in the state of Connecticut (USA) providing educational services from preschool through adult learners in the 36 school districts located in northeastern Connecticut. With funding through the Connecticut Department of Education Interdistrict Grant Program, SPIE outreach grants and the OSA Foundation, the authors have been developing and presenting standards-based lessons in waves, sound and light to fifth graders since 2007. ${ }^{1}$ While some of the lessons are completed by small groups in the classroom, others take place in large settings like Jr. Laser Camp, a yearly optics event at Three Rivers Community College for up to 150 students . Here, college students are the facilitators for a variety of activities lasting only 50 minutes each. Although the fifth grade students enjoy being on a college campus and exploring many different activities in Jr. Laser Camp, it is not clear how much they are actually learning during one day of whirlwind activities. However, the teachers believe that a day in the college setting and classroom environment provides the students with a much-needed early exposure to college, making the event worthwhile despite questions about the lasting effect of science instruction.

For the 2014-2015 school year, we decided to concentrate efforts on a single optics principle: reflection. In order to have appropriate lessons, we began with a brief survey to ascertain teachers' and students' understanding (or misunderstanding) of the reflection of light. Lessons were then developed to address the misunderstandings revealed in the pre-survey. The efficacy of the lessons was assessed through two post-surveys, one 1-2 weeks after the lessons were delivered and one 6-8 weeks later. Two of the pre-survey questions were adapted from a 2009 study of elementary and middle school teachers' understanding of topics in light (reflection, refraction) and motion. ${ }^{2}$ Fewer than $60 \%$ of teachers were able to correctly trace the path of a ray of light reflected from a mirror and only about $40 \%$ were able to apply the law of reflection to a situation involving an image in a mirror. Our hypothesis was that fifth graders would have at least the same amount of difficulty with these questions in the pre-survey.

The third survey question was inspired by conversations with students who seemed unsure of how the eye uses light for vision. The question "which of the following reflects light?" was intended to determine if students realized that light must be reflected from an object into the eye in order to be seen. Studies have indicated that an alarming number of children and adults (including college students who have taken a psychology course in perception) believe that vision includes some sort of emanations from the eyes. ${ }^{3,4}$ This view is consistent with the extramission theory of vision developed by early Greek philosophers. While not addressing the process of vision directly, this question probed students understanding of one aspect of vision, that light must be reflected from non-luminous objects in order to see them.

\section{PRE-SURVEY RESULTS}

The pre-survey data provided a baseline of knowledge regarding the preparation of the teachers to teach content and preconceived ideas of the students. Students from seven fifth grade (ages 10-11) classrooms (N=141) were given the presurvey prior to receiving any instruction on reflection. (See Figure 1.) Only six of the classes were actually involved in the lessons, three fifth grades from each of two schools. The seventh school did not attend the lessons and did not take

*nmagnani@eastconn.org www.eastconn.org

Education and Training in Optics and Photonics: ETOP 2015, edited by Eric Cormier, Laurent Sarger Proc. of SPIE Vol. 9793, 97931X · @ 2015 SPIE, IEEE, OSA, ICO · doi: 10.1117/12.2223185 
the post-survey. Eleven teachers also answered the pre-survey questions; however, there was no attempt to explicitly provide professional development to the teachers. They did remain in the classroom, however, and took part in the lessons along with students. We noted that of the eleven teachers, 10 had the correct answer on question 1, 4 on question 2 and 7 on question 3.

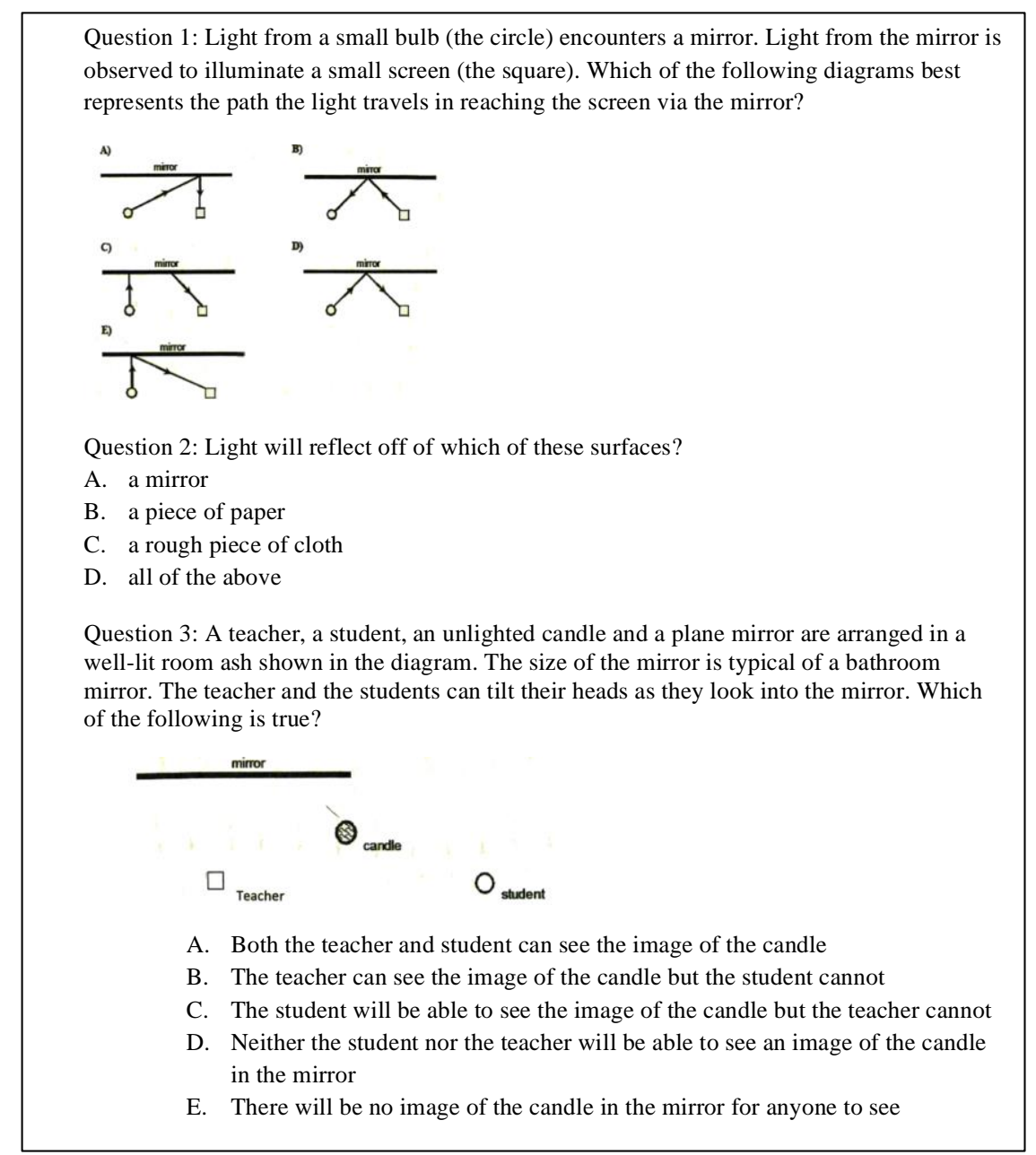

Figure 1. The three pre-survey questions. Questions 1 and 2 are adapted from Krall, Christopher, Atwood 2009.

Student scores on the pre-survey varied greatly by classroom as shown in Table 1 . Because the language used in the questions was almost the same as that used with teachers in the original 2009 study, it may be that students with low reading levels were unable to understand the language or concept of the questions. However, the students did show a consistency in choice of wrong answer.

The most common incorrect answer on the first question (the law of reflection) showed the path of light in reverse, that is, from the screen to the bulb. It is not clear if this is an example of students' belief that light travels from the eyes to an object in order to see or if they simply did not notice the direction of the arrows on the rays and chose this answer because it was the first in the list that looked superficially correct. By far the favorite incorrect answer on the second question was that mirrors reflect light. This may have been the mistaken belief that surfaces that are not shiny do not reflect, or it may have been chosen because it was the first answer and clearly mirrors reflect light. The most popular incorrect answer on question 3 was that both teacher and student could see the mirror. 
Table 1. Student scores on pretest, percent of students with the correct answer.

\begin{tabular}{|c|c|c|c|}
\hline Survey Question & $\begin{array}{c}\text { Worst class performance } \\
(\% \text { correct })\end{array}$ & $\begin{array}{c}\text { Best class performance } \\
(\% \text { correct })\end{array}$ & $\begin{array}{c}\text { Average \% correct. } \\
\text { N=141 students }\end{array}$ \\
\hline 1 & $37 \%$ & $73 \%$ & $52 \%$ \\
\hline 2 & $0 \%$ & $21 \%$ & $7 \%$ \\
\hline 3 & $22 \%$ & $45 \%$ & $33 \%$ \\
\hline
\end{tabular}

\section{LESSONS TO ADDRESS THE MISUNDERSTANDING OF REFLECTION}

Based on student responses we developed two sets of inquiry-based lessons, each consisting of several activities: 1) a quantitative lesson (discover the law of reflection) and 2) a qualitative lesson (what reflects light?). Students from the two schools that are the subject of our study met two classes at a time for a one-day workshop with 40-45 students. Students from the two schools had been corresponding prior to the workshop and had "partners" that they worked with during the day, with groups of two partners forming a team of four for the lessons. By breaking the presentations into smaller numbers of students, it provided us with the opportunity to pay more personal attention to students and to present the workshop three times on separate days and evaluate and adapt the presentation. As far as possible, workshops were identical except as noted: One of the authors was unable to attend the first workshop and was replaced for the qualitative lesson by a substitute facilitator who is not a science educator. Due to other time constraints, the quantitative lesson was not completed in this same workshop.

Although it would have been preferable for all students to begin with the qualitative lesson and then move on to the quantitative lesson, space limitations required that a separate classroom be set up for each set of lessons. In a classroom setting that is not designed for science instruction there are limitations to materials and the physical space, for example, students worked at desks rather than tables. After gathering in the cafeteria to meet their partners and work on a teambuilding activity, students moved to one of the classrooms for the morning and then switched classrooms after lunch, resulting in some students performing the qualitative lessons first and some the quantitative lessons first. Each lesson lasted about one hour.

Both of the lessons included vocabulary words that students needed to master in order to successfully complete the activities and these were introduced before any experimentation and reviewed as they were encountered in the lessons. Each of the activities required recording data and observations, and group discussions were held after each activity to elicit feedback and make sure all students were observing what was expected.

\subsection{Quantitative lesson: What reflects light?}

Students were first asked to look at a specific object in the room for a few minutes and think about and write down all the sources light that illuminated it. (Illuminate was one of the lesson's vocabulary words.) All students reported the obvious light sources- light fixtures in the room, sunlight, light entering from the hallway- and some also noted computer monitors and LED indicator lights. Interesting, "solar panels on the roof" were mentioned by several students, leading to a discussion of the relationship between light and the production of electricity (solar panels) and electricity and the production of light (fluorescent bulbs in the ceiling).

Next, each group of students was given a small tomato and keychain LEDs in red, green and blue plus an ordinary flashlight. The room was darkened and students were told to shine each light in turn on the tomato and write down what color the tomato appeared with that illumination. In the discussion that followed, students expressed the idea that color depends both on the color of the illuminating light source and the surface properties of the object.

The third activity was to determine if a Styrofoam ball can reflect light. A mirror clearly reflects a beam from a flashlight; this can be illustrated by shining a flashlight onto a mirror and viewing the reflected light on a wall or screen. To determine if rough-textured objects can reflect light, each group was given a small (about $8 \mathrm{~cm}$ diameter) white Styrofoam ball and a flashlight and asked to predict if Styrofoam can reflect light. To test their hypotheses students shined the flashlight upward at an angle and moved the ball into place over it, intercepting the beam. As they moved the 
ball into place they watched the desk underneath to see if any light was reflected onto it. This was the "test" used in the final activity to determine if a given object could reflect light. (Figure 2)

The final activity was to test whether light is reflected from a variety of common materials: flat pasta, pieces of foam, fabric, paper, plastic, aluminum foil and more. Students first sorted the items into three categories: shiny, rough and dull, and then tested each object using the flashlight method. In some cases students needed to figure out how to fairly test some of the smaller objects, for example, a pipe cleaner could be bent into a flat shape so that reflected sufficient light to see on the table. After expressing surprise that all of the items in the collection reflected light to some degree, students spontaneously tried to determine if other items- such as their own hands or arms- were similarly reflecting.

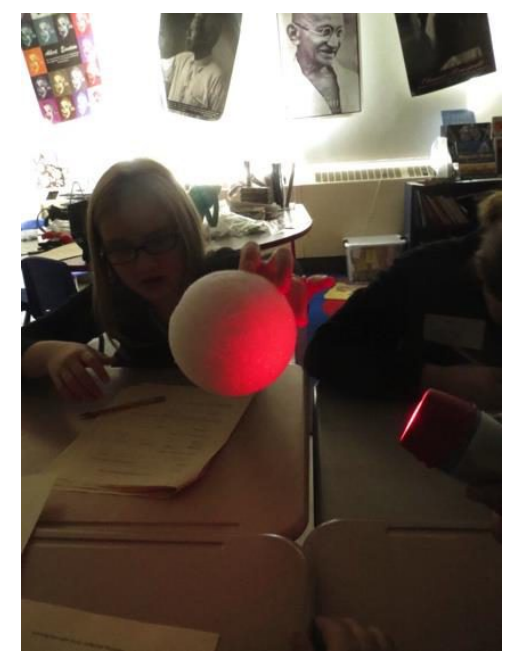

Figure 2. Students perform the "reflection test" with a red flashlight and a Styrofoam ball.

\subsection{Quantitative lessons: The law of reflection}

Students were given small rectangular plastic mirrors that could stand vertically (they were taped to small blocks), a laser pointer and printed paper protractor. After reviewing the use of a protractor to measure angles, students recorded the reflected angle for various incident angles and determined that the reflected angle is equal to the incident angle. They were not explicitly told the law of reflection, but discovered it for themselves. (See Figure 3.) An animated PowerPoint presentation was used to show how the law of reflection applies to smooth (specular) and rough (diffuse) surfaces.

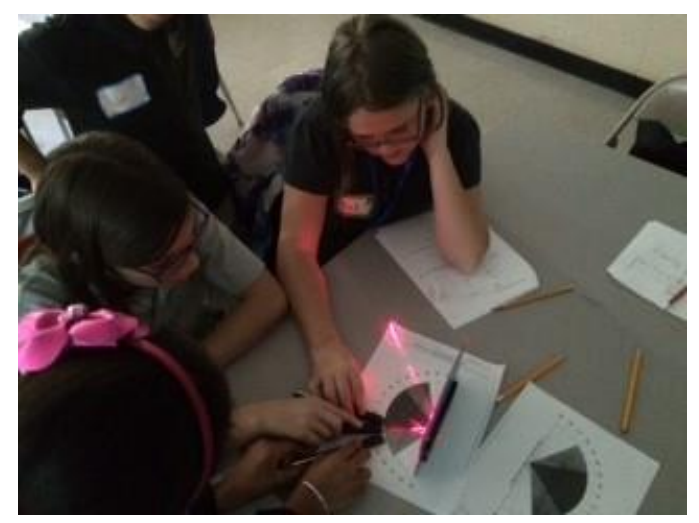

Figure 3. Students use a laser pointer, mirror and protractor to discover the law of reflection

To test understanding of the law of reflection, an activity was developed to illustrate question 3 in the pre-survey. A lightweight wall mirror, about $34 \mathrm{~cm} \times 127 \mathrm{~cm}$, was placed on the chalk tray, vertically against the wall. The mirror was covered so students could not see any reflection. Standing in pairs with the facilitator holding a stuffed bear in between as shown in Figure 3a, students were asked to predict who would be able to see the bear. After testing their guesses, the mirror was moved to the position shown in Figure $3 \mathrm{~b}$ and the process was repeated. Using the law of reflection it was possible to show how only one student could now see the toy (Figure 3c). 


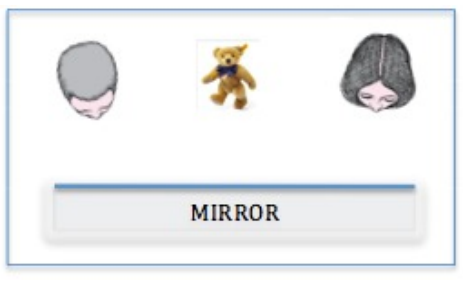

(a)

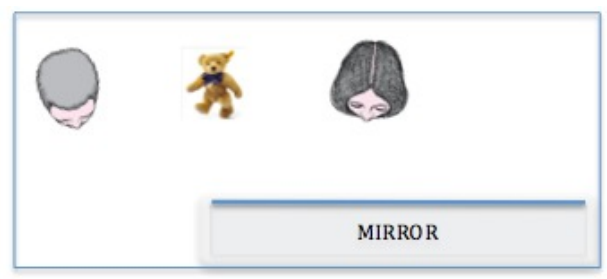

(b)

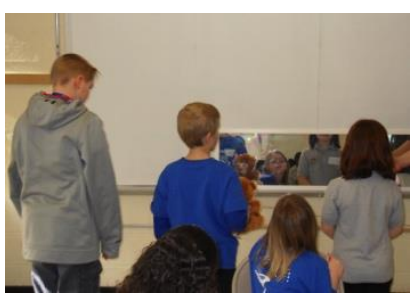

(c)

Figure 3. a) Students predict who can see the teddy bear with students at the ends of the mirror and the bear between them. b) The mirror is shifted to the right to the position shown and students are again asked to predict who can see the teddy. c) Students performing the activity.

\section{WORKSHOP EVALUATION}

\subsection{Student comments}

As a concluding activity, students were asked to write a reflection on the day's activities. The prompts were to state "something that surprised me" and "one thing that you learned that was new". Students were asked in the remaining time to write a story about light, either factual or fictional. Typical responses include:

The thing that surprised me was everything can reflect light. (There were many variations of this theme.)

Something that surprised me is that anyone can be a scientist at any age.

Today the most surprising thing was even rough objects reflect light.

One thing that I learned was new was that 2015 was the year of light.

What I learned that was new is that something can be one color but if you mix it with another color or light it looks totally different.

I learned that everything rough, dull and shiny reflect light. If it didn't you wouldn't be able to see the item.

Because the workshops were held soon after the opening ceremonies of the International Year of Light in Paris, students were told about that exciting event and introduced to some of the ideas presented in the keynote addresses, including a brief introduction to Ibn al-Haytham's work on light and vision. In fact, the opening exercise in the qualitative lesson (thinking about the sources of light that illuminate an object) was inspired by an IYL2015 blog entry. At the end of the day, some of these ideas emerged in student stories of light. Here are two examples:

My light. One day I thought about light. So, I went on my computer to look it up. A guy named Ebenall Hafen (sic) came up on the screen. I clicked the name and read. I learned that light came from people, like engineers, and from the sun. People make light in factories or by hand. Some light is new, like light bulbs. Some are old, like fire.

Light is a beautiful thing. It can be different colors, help plants grow and gives us the life we have today. Light bounces off the object or reflects off an object back to your eyes. Light has been around for years, picture the first plant. Light had to be there for it to grow, then it developed and could be added to houses. Light is a wonderful thing. Evenal Haffen (sic) was the person who figured out how light worked. Before people thought it came from their eyes. But he discovered it didn't! 


\subsection{First post workshop survey}

Approximately two weeks after the workshop, teachers were asked to have students complete a post-survey, identical to the pre-survey. Although we felt the survey needed editing to be more appropriate to fifth grade, we decided to use the original survey for a better pre-post comparison. The results in Table 2 include only the six classrooms that participated in the workshops $(\mathrm{N}=123)$.

Improvement was seen across all three questions, although the improvement for question \#1 was slight and probably not significant. Again, students may have not noticed the directions of the small arrowheads and chose the first diagram where the two angles were equal. The improvement was even more pronounced if the results for students instructed by the facilitator with no science background are removed. It is not clear that this facilitator understood the point of the lesson or knew how to ask probing questions to ascertain student understanding. Still, only 38\% of students answered correctly that objects other than mirrors can reflect light, even with an experienced facilitator.

Table 2 - Pre/Post Survey results, percent with correct response to question. The first post-survey results are for all six classes, the second post-survey column does not include students instructed by the facilitator with no science background.

\begin{tabular}{|c|c|c|c|}
\hline Survey Question & Pre survey & $\begin{array}{c}\text { Post survey (N=120) } \\
\text { (both facilitators) }\end{array}$ & $\begin{array}{c}\text { Post survey (N=80) } \\
\text { (experienced facilitator only) }\end{array}$ \\
\hline Question 1 & $53 \%$ & $56 \%$ & $55 \%$ \\
\hline Question 2 & $8 \%$ & $28 \%$ & $38 \%$ \\
\hline Question 3 & $34 \%$ & $53 \%$ & $59 \%$ \\
\hline
\end{tabular}

\subsection{Second workshop post-survey}

It is not surprising that students' understanding of a topic, in this case reflection, shows improvement in a post-survey or test given directly after instruction. But how much is remembered six weeks or more after the workshop? To get a sense of how well students understood and remembered reflection concepts, we asked teachers to give a second post-survey 68 weeks after the workshops. We hoped that students would score at least as well as they did in the survey immediately after the workshop, but were prepared to find that some students had already forgotten the lessons.

Although the question content was the same in the second post-survey, the graphics were improved to be more studentfriendly: on Question 1 the arrows were larger and the circle and square were replaced by graphics of a bulb and a screen, and on Question 3 we replaced squares and circles with graphics of people and a candle). The answers for Question 2 were scrambled so that the obvious "mirror" was not first in the list. The wording was also edited to be more appropriate to fifth grade readers. For this reason, the results of the two post-surveys are not directly comparable. (See Table 3.)

Table 3 - Pre/Post Survey results, percent with correct response to question.

\begin{tabular}{|c|c|cc|}
\hline Survey Question & Pre survey & Post-survey at 1-2 weeks & Post-survey at 6-8 weeks \\
\hline Question 1 & $53 \%$ & $56 \%$ & $75 \%$ \\
\hline Question 2 & $8 \%$ & $28 \%$ & $35 \%$ \\
\hline Question 3 & $34 \%$ & $53 \%$ & $52 \%$ \\
\hline
\end{tabular}

We were pleased to see the large improvement in responses to Question 1 (law of reflection) and Question 2 (what reflects light?). We believe the improvement in Question 1 was due to better graphics making it clear that answers B and D (in Figure 1) were not the same. In Question 2, encouraging students to read all of the choices may have reminded them of the activity where they tested the reflectance of rough objects. We saw no change in the level of correct responses for Question 3, even with the more student-friendly graphics. Several students attempted to use the law of reflection to determine who could see the image in the mirror, although in some cases they drew rays from the person to 
the object not the other way around. Student who answered Question 1 incorrectly used their incorrect version of the law of reflection to try to solve this problem as well.

Although we would have like to see a higher percentage of students choosing the correct answers, we were encouraged in this first attempt with these lessons with the improvement between pre and post surveys.

\section{CONCLUSIONS}

Targeted instruction, including both qualitative and quantitative lessons, was shown to improve student understanding of reflection concepts. Instruction must be facilitated by instructors who are familiar with the material and who can appropriately correct student errors and answer student questions.

\section{ACKNOWLEDGEMENTS}

Thanks to:

The PHOTON email listserv for suggestions for the lesson that all all objects reflect light.

Students from the fifth grade classrooms of Audrey Aresco, Carol Fellenstein and Paola Maina at O'Connell School, East Hartford, CT USA.

Students from the fifth grade classrooms of Kevin Devery, Kelly Everett, and Cheryl Spencer at Skinner Road School, Vernon, CT USA.

\section{REFERENCES}

[1] N. Magnani and J. Donnelly, "Optics in Eastern Connecticut," in Education and Training in Optics and Photonics, OSA Technical Digest Series (CD) (Optical Society of America, 2009), paper EMCA3.

[2] Krall, Rebecca McNall; Christopher, John E.; Atwood, Ronald K., "Comparison of Central Appalachian In-Service Elementary and Middle School Teachers' Understanding of Selected Light and Force and Motion Concepts", Science Educator, v18 n1 p1-16 Spr 2009

[3] Winer GA1, Cottrell JE, Gregg V, Fournier JS, Bica LA., "Fundamentally misunderstanding visual perception. Adults' belief in visual emissions", Am Psychol. 2002 Jun-Jul;57(6-7): 417-24.

[4] Gregg, V.R., Winer, G. A., Cottrell, J. E., Hedman, K. E.,Fournier, J. S., " The persistence of a misconception about vision after educational interventions ", Psychonomic Bulletin \& Review 2001, 8 (3), 622-626. 